F. Grattepanche $\cdot$ C. Lacroix $\cdot$ P. Audet $\cdot$ G. Lapointe

\title{
Quantification by real-time PCR of Lactococcus lactis subsp. cremoris in milk fermented by a mixed culture
}

Received: 28 October 2004 / Published online: 18 November 2004

C) Springer-Verlag 2004

\section{Appl Microbiol Biotechnol (2004) D0I 10.1007/ s00253-004-1822-0}

In the Materials and methods section, subsection Oligonucleotide primers and real-time PCR quantification, the sequence of the specific primer $68 \mathrm{FCa} 33$ should read:

5'-GAT GAA GAT TGG TGC TTG CAC CAA TTT GAA GAG-3'

The online version of the original article can be found at http://dx. doi.org/10.1007/s00253-004-1705-4

F. Grattepanche · G. Lapointe ( ()

STELA Dairy Research Centre, Pavillon Paul Comtois,

Université Laval,

Québec, QC, G1K 7P4, Canada

e-mail: gisele.lapointe@fsaa.ulaval.ca

Tel.: +1-418-6562131

Fax: +1-418-6563353

C. Lacroix

Institute of Food Science and Nutrition, Swiss Federal Institute

of Technology,

ETH Zentrum, Zurich, 8092, Switzerland

P. Audet

École des sciences des aliments, de nutrition et d'études familiales, Pavillon Jacqueline Bouchard, Université de

Moncton,

Moncton, NB, E1A 3E9, Canada

G. Lapointe

Nutraceuticals and Functional Foods Institute, Pavillon de

l'INAF, Université Laval,

Québec, QC, G1K 7P4, Canada 